\title{
LA ESPIRITUALIDAD SACERDOTAL
}

\author{
JOSÉ MARÍA YANGUAS
}

El desarrollo del tema propuesto ha de tener necesariamente un carácter sumario. En esta breve reflexión' sólo deseo ofrecer el marco general en el que, en mi opinión, deben situarse los intentos de una respuesta más a fondo de la cuestión de la existencia de una espiritualidad sacerdotal. Precisar sus rasgos es algo de lo que no me puedo ocupar aquí.

La pregunta por la eventual espiritualidad sacerdotal supone haber solucionado previamente y de manera satisfactoria algunas otras cuestiones de alcance más general. Sólo con su acertada resolución se despeja el horizonte en el que se puede buscar una respuesta, al menos aproximada, a la pregunta que aquí nos hacemos. Me limitaré a señalar dichos problemas con el fin de no apartarme del fin que me he propuesto.

1. ¿Es posible, y en qué sentido, hablar de diversas espiritualidades en la Iglesia? ¿Qué se entiende exactamente por 'espiritualidad'? En el caso de que existan, ¿cuál o cuáles son los criterios diferenciadores? ¿No es una y la misma la santidad a la que todos estamos llamados? ¿No son los mismos para todos los medios de que disponemos para alcanzar dicha santidad? ¿No es cierto que Jesucristo es el único camino para acceder al Padre, guiados por el Espíritu, y que El es el modelo en el que todo cristiano debe mirarse, y única la enseñanza en cuyo aprendizaje y vivencia todos por igual hemos de comprometernos?

Repito que no pretendo entrar en la discusión de tales preguntas. Pero una respuesta inicial, al menos, viene ofrecida por el capítulo $\mathrm{V}$ de Lumen gentium, que se ocupa de la universal llamada a la santidad. Allí se establece que la santidad a la que todo cristiano está llamado es única: «El Señor Jesús, maestro y modelo 
de toda perfección, ha predicado la santidad de vida a todos y cada uno de sus discípulos sea cual fuere su condición, santidad de la que El mismo es autor y perfeccionador» (n. 40). En el mismo número queda definida dicha santidad como «plenitud de la vida cristiana" y "perfección de la caridad». Todo hombre se convierte por el Bautismo en hijo de Dios y en participante de la vida divina $y$, por ello, es ya, verdadera y radicalmente, santo. Participando de la plenitud de la gracia de Cristo, el cristiano es conducido por el Espíritu Santo hacia la plenitud recibida incoativamente en el Bautismo.

No deja el Concilio de señalar la manera o el camino a recorrer para lograr dicha plenitud cristiana; en efecto, "para alcanzarla, dice, los fieles deben usar las fuerzas recibidas según la medida con que Cristo ha querido enriquecerles, para que, siguiendo su ejemplo y conformándose a su imagen, obedientes en todo a la voluntad del Padre, se consagren con plena generosidad a la gloria de Dios y al servicio del prójimo» (L.G., 40).

Una es pues la santidad que se propone a todo cristiano y uno el camino para alcanzarla. Ahora bien, su ejercicio y realización existencial debe cumplirse de acuerdo con el género de vida y los deberes particulares que incumben a cada uno. Cada cristiano está llamado a desarrollar y perfeccionar en su vida la santidad recibida sirviéndose de fuerzas donadas en diverso grado y de acuerdo con los propios dones (L.G., 40).

Es en este cuadro suministrado por el Concilio donde se debe situar la cuestión de la espiritualidad sacerdotal. El momento de la distinción dentro de la unidad de la santidad cristiana viene señalado por la variedad de los géneros de vida y los distintos oficios que integran la rica y pluriforme vida de la iglesia. Así parece sugerirlo, en efecto, Lumen gentium cuando afirma: «En los varios géneros de vida y en las distintas profesiones, una es la santidad que practican todos aquellos que son movidos por el Espíritu de Dios, y obedeciendo a la voz del Padre y adorándolo en espíritu y verdad siguen a Cristo pobre, humilde y cargado con la Cruz, para ser merecedores de participar de su glorias (n. 41).

Son los diversos modos de vida y la diversidad de profesiones, los diferentes modos de ser Iglesia y de realizar su única misión, los que diversifican los elementos de unidad comunes a todos 
los fieles cristianos. La Iglesia es, en efecto, Pueblo de Dios, realidad mistérica estructuralmente plural en la que se encarna el misterio "escondido desde todos los tiempos en Dios", el proyecto salvífico divino que ha querido elevar a todos los hombres a la participación de su vida divina (L.G., 2). En la estructura del único cuerpo místico de Cristo brilla una diversidad de miembros y oficios; si todos los elementos que estructuran el ser visible de la Iglesia son animados por un mismo Espíritu y se constituyen así en una unidad orgánica, cada uno de ellos es animado en su propia función particular y en la ejecución de su propio oficio.

Tanto la imagen de Pueblo de Dios, como la de Cuerpo místico, ponen inmediatamente de manifiesto la diversidad de oficios, de tareas y de misiones dentro de la Iglesia, y se traducen, a su vez, en pluralidad de deberes y de modos concretos de encarnar la vida del Espíritu que unifica a toda la comunidad de los creyentes en Cristo. El Concilio Vaticano II, tras ocuparse en la Lumen gentium de la Iglesia como realidad mistérica, y de la Iglesia como Pueblo de Dios, en los capítulos III, IV y VI contempla los tres grandes tipos de miembros que integran la Iglesia: jerarquía, laicado y religiosos. Todo lo que, en el cap. II, se ha dicho del Pueblo de Dios vale igualmente para los tres tipos de miembros de la Iglesia; ahora bien, la particular condición y misión de cada uno obliga a hablar de ellos por separado. En el n. 30 se afirma explícitamente: «Aunque lo que se ha dicho del Pueblo de Dios se dirige igualmente a los laicos, a los religiosos y al clero, sin embargo, en razón de su condición y misión, a los laicos pertenecen en particular algunas cosas cuyos fundamentos requieren ser más cuidadosamente ponderados, debido a las peculiares circunstancias de nuestro tiempom.Y en el n. 43 se dice de los religiosos: «Si atendemos a la constitución divina y jerárquica de la Iglesia, tal estado (el religioso) no es algo intermedio entre la condición clerical y laical, sino que de entrambos, algunos fieles son llamados por Dios a gozar de este particular don en la vida de la Iglesia y ayudar, cada uno a su modo, en su misión salvífica».

He aquí, pues, el primer elemento configurador de las variadas formas de vivir la llamada común a la santidad, el compromiso radical cristiano que lleva a luchar en pro de una identificación plena con Cristo y a alcanzar de ese modo la plenitud de la vida cristiana. 
Pero que sea el primero no significa que sea el único. De acuerdo con ese primer elemento, podríamos hablar de una triple espiritualidad en el seno de la Iglesia: de los pastores o pastoral, laical y religiosa, teniendo en cuenta que el ejercicio de la santidad, su real prosecución y su encarnación existencial, viene diferenciada, según el Concilio, a tenor del puesto eclesial ocupado por cada uno de los cristianos. Son, pues, en primer lugar las tareas eclesiales, la participación diversa en la única misión de la Iglesia, lo que permite hablar de distintos ejercicios de la santidad cristiana.

2. Ahora bien, si las distintas modalidades del ser Iglesia y participar en la misión que le ha sido confiada por el Redentor llevan consigo un ejercicio peculiar, a ellas apropiado, de vivir la única santidad a la que todos estamos llamados, nada impide, en principio, pensar en que la libérrima distribución de los dones y gracias divinas otorgue a determinados miembros de la Iglesia unas tareas particulares que, dentro de cada uno de los tres modos señalados de ejercicio de la santidad cristiana, lleven consigo modulaciones singulares en la búsqueda de la santidad, de acuerdo con las exigencias propias que representan los carismas recibidos.

En efecto, si es la misión confiada a cada uno lo que parece ejercer de elemento básico configurador del ejercicio de la santidad, junto a la división de funciones fundamentales establecida por el mismo Señor o ratificada por la Iglesia, dicho ejercicio variará en razón de los dones y carismas que Dios reparte en su Iglesia para que ésta pueda conseguir el fin que su mismo Fundador le confirió y de los que hace depositarios a determinadas personas, a la vez que les exige el hacerlos fructificar en beneficio de todo el Pueblo de Dios y de la humanidad.

La riqueza de los caminos estructurales en el ejercicio de la santidad se ve así acrecentada por los sucesivos carismas que el Espíritu regala a su Iglesia. Los fines particulares que son llamados a cumplir determinadas personas condicionan su modo de vida $y$ el uso de los medios universales de santificación, de acuerdo con aquellas necesidades que vienen a paliar, con los aspectos de la vida cristiana que ponen de relieve, etc.

3. No se debe tampoco dejar en la sombra el hecho de que los diferentes carismas eclesiales, estructurales de la vida de la Iglesia o no, recaen siempre sobre sujetos bien determinados, con do- 
tes, temperamentos y caracteres delimitados y precisos que hacen que la santidad auténtica revista siempre en la Iglesia el aspecto de lo irrepetible y único. Hablar de espiritualidad, al menos en su sentido usual, sugiere justamente la idea de un ejercicio de la santidad que presenta rasgos comunes, idéntica flexión en determinadas verdades de la fe, acentos originales en el vivir cristiano, características afines a un número más o menos elevado de personas. No conviene olvidar por tanto, que es el Espíritu Santo el verdadero santificador y el que conduce a cada uno de los hombres por caminos irrepetibles, por más que se inscriban dentro de unas líneas generales, comunes a otros cristianos. La actividad santificadora del Paráclito no es nunca una producción seriada, trabajo indiferenciado sobre una materia sólo cuantitativamente diversa, sino, muy al contrario, original e imprevisible labor bien diferenciada, y ello aunque en base a una vocación compartida o de características semejantes se puedan descubrir los rasgos comunes de una misma orientación o inspiración común en el camino de la santidad. El canto de alabanza a Dios que se alza de la vida de los hombres que se esfuerzan por hacer rendir los talentos recibidos ejecuta una misma melodía, actualizada sin embargo en múltiples y armoniosas formas. En ese canto de alabanza no sólo es posible diferenciar la distinta ejecución de cada una de las 'cuerdas', sino que cada una de las voces, aun dentro y en el conjunto de las voces similares, reproduce la melodía en manera absolutamente única. La vida cristiana y sus exigencias universales, las distintas espiritualidades -modulación específica en la vivencia de tales exigencias- terminan por ser vividas en último término de manera completamente novedosa por cada cristiano.

4. Tras lo dicho, parece claro que existe una espiritualidad sacerdotal, un ejercicio de la santidad propio y peculiar de los sacerdotes o, para decirlo de un modo más general y más exacto, propio de los pastores del Pueblo de Dios. Como hemos subrayado, es la misión confiada por Dios a cada uno dentro de la Iglesia y del mundo la que actúa como elemento diferenciador, pues la entera vida personal ha de ser puesta al servicio de la tarea confiada. Así parece afirmarlo el Concilio. Dejando aquí de lado lo que concierne a los Obispos, el Concilio delinea en el n. 41 de Lumen gentium el peculiar ejercicio que corresponde a los pastores en la prosecución de la santidad a la que todos estamos llamados. Las líneas maestras que configuran el ejercicio sacerdotal de la santidar. 
pueden ser elencadas del siguiente modo a tenor del texto conciliar indicado:

-el ejercicio cotidiano del propio oficio como camino para crecer en el amor a Dios y al prójimo; en él deben proceder hacia una mayor santidad (cfr. también Presbyterorum Ordinis, 12);

-el vínculo de la comunión en el sacerdocio que regula las relaciones mútuas (cfr. P.O., 8);

-la fiel unión y generosa cooperación con el propio Obispo, que contribuye en gran manera a la propia santificación (cfr. P.O., 7 y 15).

Si todos los fieles cristianos están llamados a la plenitud de la vida cristiana y a la perfección de la caridad, y para alcanzarla han de emplear todas sus fuerzas según los dones recibidos; si cada uno debe avanzar por el camino de las virtudes según los propios dones y funciones, entonces el ejercicio de la santidad del sacerdote debe discurrir necesariamente por las líneas recién indicadas, ya que vienen inmediatamente establecidas por el munus ministerii sui (L.G., n. 28). En efecto, en virtud de la consagración sacerdotal, los presbíteros están llamados a predicar el evangelio, a apacentar el pueblo fiel y a celebrar el culto divino. Por dicho título, los sacerdotes quedan asociados, en comunión jerárquica, al orden de los Obispos; y en virtud de la común ordenación, los presbíteros se unen entre ellos en una íntima fraternidad, de la que brotan como espontáneamente manifestaciones distintas de afecto y mutua ayuda.

El modo singular en que los sacerdotes han de vivir la llamada universal a la santidad queda precisado y delimitado por esos trazos básicos, fundamentales y constituyentes de la espiritualidad sacerdotal.

5. ¿Se puede hablar todavía de una pluralidad de espiritualidades sacerdotales? La respuesta me parece que debe ser afirmativa. El marco que se acaba de bosquejar, definitorio de una específica espiritualidad sacerdotal, no excluye el hecho de que las exigencias más concretas que de él se derivan puedan ser articuladas en formas diversas. Nada impide hablar de una espiritualidad laical o religiosa específicas, que ofrecen unos rasgos básicos necesarios e indispensables, sin que por ello tenga que negarse que la pluralidad de sus concretas exigencias, la disposición de los medios y subsi- 
dios para llevarlas a la práctica, pueda armonizarse en formas distintas que, respetando las líneas maestras, constituyen justamente su vital, existencial y multiforme realización, de acuerdo con los dones y carismas que libérrimamente Dios otorga a su Iglesia en vistas al logro de su misión y de acuerdo con las mudables necesidades y circunstancias de los hombres.

La realidad de tal supuesto parece no admitir discusión histórica alguna ante el hecho de las diversas familias y espiritualidades «religiosas», con claras notas diferenciadoras dentro de la común espiritualidad «religiosa»: la conjugación del carisma que podemos llamar estructural-eclesial y de los carismas personales ha dado lugar históricamente a variadas realizaciones de la vida religiosa. Nada parece que pueda impedir el pensar en un fenómeno semejante dentro de una genuina espiritualidad sacerdotal o laical.

Firmes los rasgos básicos estructurales del existir pastoralsacerdotal definidos en virtud de la consagración y correspondiente misión de los Pastores dentro de la Iglesia y en el seno de la humanidad, resta abierta la insospechada y siempre nueva actuación del Espíritu Santo, que reparte sus dones y carismas de acuerdo con las necesidades de los hombres y de los tiempos, carismas que reciben un carácter más o menos oficial dentro de la comunidad eclesial.

Cabe pues, para concluir, hablar de una espiritualidad o ejercicio de la santidad cristiana propio de los sacerdotes - de los pastores-, a condición de dejar espacio a la realización concretaexistencial, plural y variada, de dicha espiritualidad, y siempre que ésta encarne efectivamente los rasgos constituyentes del existir sacerdotal. Pretender, por tanto, que la precisa definición de la espiritualidad sacerdotal exija, ex natura sua, una monolítica y rígida, única y uniforme realización de tal espiritualidad, supondría afirmar un presupuesto tan poco convincente como el de quien, conocidos y analizados los rasgos definitorios de la naturaleza humana, pretendiera establecer a priori la necesidad de una absoluta y repetitiva igualdad entre los hombres: grande sería su asombro al descubrir la plural riqueza de las distintas razas, los diversos tipos nacionales y la variación imprevisible del tema bumano en su realización individual. 
